\title{
Sistema de Transmissão por Fibra Ótica para uso Didático ${ }^{1}$
}

\author{
Juán Carlos Luna, Juán Carlos Alvarez, Pedro Vizcaya Guarin \\ Pontifícia Universidad Javeriana, Bogotá - Colombia
}

Angela Maria Guzmán

Universidad Nacional de Colombia, Bogotá - Colombia

\author{
Hypolito José Kalinowski \\ Centro Federal de Educação Tecnológica do Paraná \\ Av. Sete de Setembro, 3165 \\ 80230-901 Curitiba, PR
}

\begin{abstract}
Desenvolvemos um sistema didático de transmissão por fibra ótica para uso nos laboratórios de graduação em Física e Engenharia. O conjunto é composto de módulos para medida da taxa de erro de bit (BER), transmissores e receptores, relógio mestre, geradores de sequências pseudoaleatórias e de ruído. A simplicidade e o baixo custo deste sistema o tornam adequado para a maioria dos laboratórios de ensino, permitindo capacitar o aluno no conhecimento das principais características dos dispositivos presentes nos sistemas de comunicações óticos.
\end{abstract}

We developed an educational system for fiber optic transmission experiments in undergraduate laboratories of Physics and Engineering. The system has boards for Bit Error Rate measurements, laser and led transmitters, photodetector receivers and noise generator. Due to simplicity of design and use of low cost components it is suitable for the majority of teaching laboratories and helps to consolidate the main concepts of optical communication systems.

Palavras chave: Ensino de Telecomunicações, Equipamentos Didáticos, Fibras Ópticas, Enlaces Ópticos.

\section{Introdução}

O rápido desenvolvimento das comunicações por fibra ótica requer uma melhor formação dos estudantes de telecomunicações, engenharia eletrônica ou física em tópicos específicos das tecnologias ali envolvidas. Citamos, como exemplo, opto-eletrônica, propriedades de fibras óticas e desempenho do sistema. No tocante a este último tópico, os sistemas óticos sāo principalmente digitais e uma das técnicas de caracterização adotadas e a medida da taxa de erro de bit. Entretanto, tal determinação

1 Manuscrito encaminhado em fevereiro de 1993; aceito de abril de 1993. 
requer um medidor adequado, que custa alguns milhares de dólares - um custo elevado para os orçamentos de laboratórios didáticos na maioria das instituições.

É possível encontrar sistemas de transmissão óticos vendidos por companhias estrangeiras voltadas ao mercado educacional. Usualmente tais sistemas operam em taxas entre 1 e $10 \mathrm{Mbit} / \mathrm{s}[1,2]$, utilizando LED's como fonte de luz devido ao seu baixo custo e a simplicidade de projeto do circuito associado. Tais sistemas são normalmente projetados para uso com fibras óticas do tipo PCS (plastic-cladded silica) ou mesmo fibras puramente plásticas. Este fato reduz o alcance de um enlace a algumas dezenas ou centenas de metros. Mesmo sendo úteis para formar o estudante na montagem básica de um sistema e com a propagação de luz não visível, tais sistemas ainda exigem um medidor de taxa de erro para caracterização de seu desempenho. Por outro lado, o uso de LED, apesar de seu baixo custo, não permite ao estudante estudar os fenômenos ligados a emissão estimulada de radiação e suas características, como é o caso de um laser semicondutor (LD).

Para controlar este último fato, professores da Eldengenossige Technische Hochschule (ETH - Zurich) introduziram um sistema educacional de transmissão ótico baseado em lasers de Compact Disk (CD)[3]. Desta forma um desempenho superior pode ser obtido e permitindo, adicionalmente, o uso de fibras óticas de telecomunicações, conectores e emendas no enlace. Uma das vantagens de utilizar um laser é permitir com o mesmo sistema o estudo de suas características, do tipo potência ótica versus corrente, efeitos de temperatura, composição espectral etc.. Entretanto, o sistema proposto na ETH-Zurich também é baseado em um medidor de taxa de erro comercial para sua utilização.

O sistema que desenvolvemos visa principalmente substituir o medidor de taxa de erro por um conjunto de módulos dedicados que realizam tal função. Desta forma é adequado para laboratórios de ensino em países em desenvolvimento. Os componentes básicos do sistema serão descritos nas próximas seções.

Devido a dificuldade de encontrar LD's no mercado interno em nossos países, realizamos módulos tanto baseados em LED's como LD's para fontes de luz. Assim o sistema, mesmo com alguma limitações, pode ser utilizado quando a disponibilidade de LD's não for adequada. Incluímos ainda um subsistema analógico, afim de permitir experiências utilizando transmissão em banda larga através de fibras óticas. Isto auxilia os estudantes nos aspectos relativos a transmissão analógica por meios óticos e com a distorção de sinal envolvida.

Não contando com o gabinete e as fontes de tensão, o sistema aqui proposto pode ser construído com aproximadamente US\$ 500, um orçamento razoável para um equipamento de fins didáticos. 


\section{Descrição do Equipamento}

O diagrama em blocos do sistema proposto é mostrado na figura 1.0 conjunto básico é formado por dois blocos, um transmissor e um receptor digitais. Alguns módulos permitem examinar o desempenho do sistema ótico: três geradores de sinais para teste (relógio mestre, gerador de sequências pseudo - aleatórias e gerador de ruído) e o medidor de BER, podendo ser utilizados de forma independente como geradores de sinais para teste ou medidor de BER na avaliação de transmissões digitais. Cada um destes módulos é rapidamente descrito adiante.

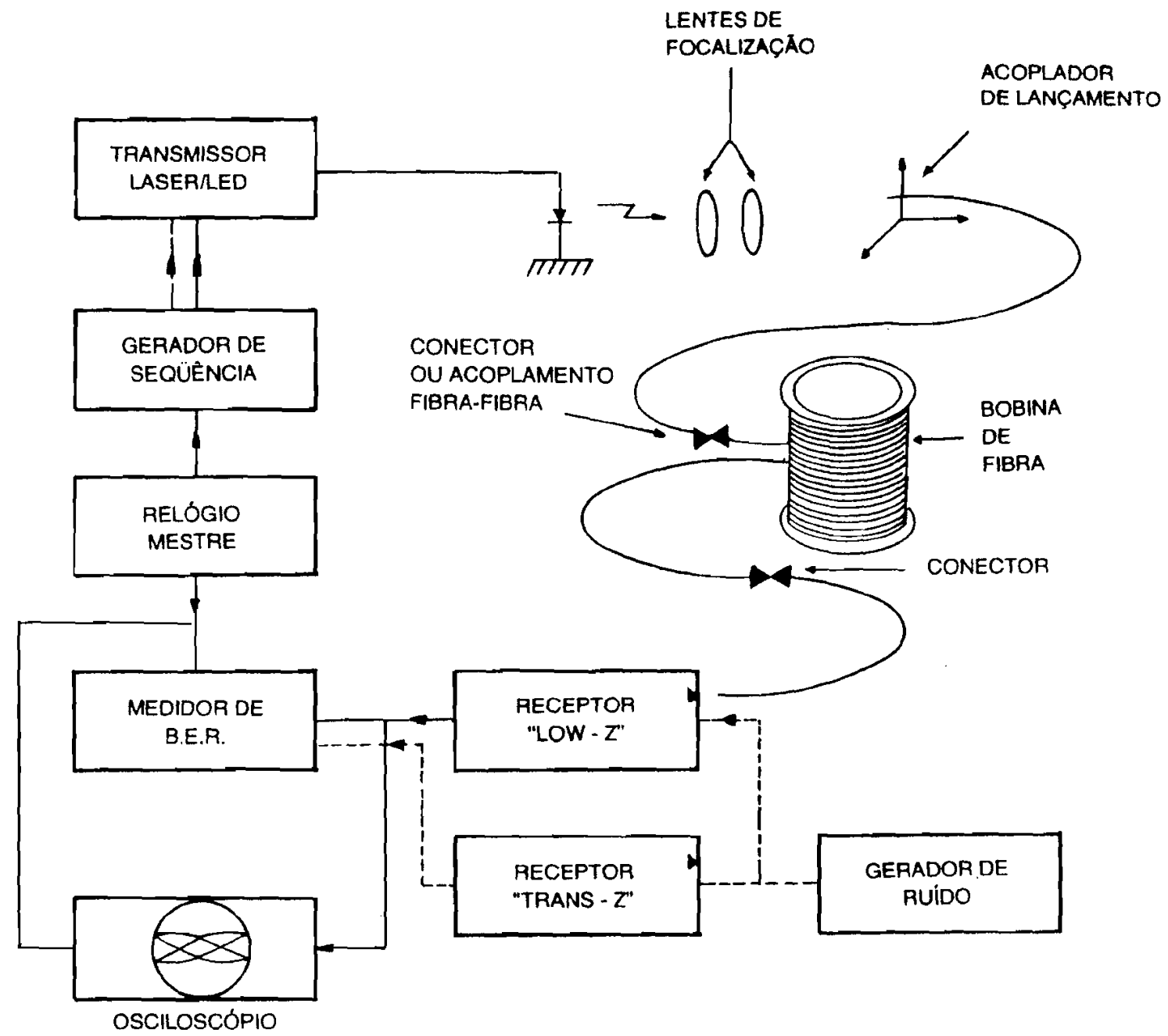

Figura 1: Diagrama em blocos do sistema de transmissão ótico para uso didático.

\subsection{Transmissores e Receptores Óticos}

Até o momento a transmissão digital tem sido a maior aplicação de fibras óticas nas telecomunicações. Uma vez que uma das maiores restrições em nosso desenvolvimento era o custo final, a fonte de luz escolhida para os transmissores básicos foi um LED 
infravermelho (830mn) da Motorola (MFOE71), da família FCLS (Fiber Low Cost Systems)[4]. A sua máxima velocidade de chaveamento é de $60 \mathrm{nS}$ e a corrente continua máxima $90 \mathrm{~mA}$. Para os receptores foi escolhido um diodo PIN (MFOD71) da. mesma família com uma responsividade de $0.2 \mathrm{~A} / \mathrm{W}$ e um tempo de resposta de $57 \mathrm{nS}$, casado espectralmente com o LED utilizado .

O transmissor digital é formado por dois buffers TTL que controlam um transistor de alta velocidade, o qual, por sua vez, chaveia a corrente através do LED. A corrente máxima pode ser ajustada entre 5 e $90 \mathrm{~mA}$ através de um potenciômetro. $O$ receptor digital é formado por um diodo PIN, seguido por dois amplificadores de voltagem lineares de banda larga. Ao longo do circuito receptor vários pontos de teste são acessíveis para medidas de chaveamento e análise de ruído utilizando um analisador de espectro. O tempo de resposta total do sistema é de $250 \mathrm{~ns}$, permitindo transmissão digital em taxas de até $4 \mathrm{Mbit} / \mathrm{s}$. A resposta do circuito receptor pode ser aprimorada pelo uso de amplificadores de melhor desempenho, entretanto mais caros e mais difíceis de serem obtidos.

Um circuito equivalente utilizando LD (Sharp LM023MC) foi realizado utilizando uma entrada direta do sinal de modulação, acoplada capacitivamente à corrente de polarização do dispositivo. Um circuito dedicado (Sharp IR3C01N) foi utilizado para manter a corrente de polarização em um nível de potência ótica média constante. Uma fonte de corrente auxiliar serve para estudo e caracterização do LD como dispositivo ótico ativo. O tipo de LD utilizado possui comprimento de onda de $780 \mathrm{~nm}$, mas apresenta uma emissão com algumas componentes na região final do vermelho, sendo assim visível o ponto luminoso quando focalizado sobre uma superfície clara em ambiente fracamente iluminado.

A transmissão analógica é também possível e eficiente através de fibras óticas, mas efeitos não lineares nos circuitos de transmissão e de recepção devem ser cuidadosamente estudados para evitar distorçōes. Em nosso conjunto um transmissor analógico foi construído monitorando com um LED a corrente de alimentação de um amplificador banda larga. A corrente polariza o LED e pode ser ajustada entre 5 e $50 \mathrm{~mA}$. O receptor foi montado por um diodo PIN seguido por um amplificador de transcondutância e dois estágios amplificadores de banda larga. A banda passante final (-3dB) disponível esta limitada a $460 \mathrm{kHz}$, embora também possa ser aprimorada por amplificadores mais velozes.

Devemos enfatizar que o uso de um LED comum limita fortemente a banda passante do transmissor analógico, o que pode ser evidenciado por um receptor de vídeo profissional. Um circuito com banda bem superior pode ser também realizado pelo acoplamento direto do sinal de vídeo de forma a modular a corrente através de um diodo laser. 


\subsection{Gerador de Relógio Mestre}

Os sinais de relógio necessários para sincronizar equipamentos externos são fornecidos por um módulo que fornece dois sinais em nível TTL, um deles de frequência variável entre 1 e $10 \mathrm{MHz}$, e outro fixo e estável (controlado por cristal) a $10 \mathrm{MHz}$. A partir de qualquer um deles é possível obter sinais derivados, utilizando um divisor decimal de até quatro décadas e um divisor binário com quatro saídas. A frequência mínima obtida neste caso é de $6.25 \mathrm{~Hz}$. Além do sinal original, um sinal deslocado em fase é também disponível para fornecer um sinal de sincronismo para propósitos de recepção.

\subsection{Gerador de Seqüência Pseudo-Aleatória}

Este módulo fornece um sinal de teste usualmente utilizado para análise do desempenho de um sistema de transmissão digital com uma sequência aleatória. Em nosso caso tal sinal é da classe denominada seqüência de duração máxima [5], que possuiu algumas propriedades ótimas em relação a sua função de autocorrelação e sua duração. Estas sequências são geradas utilizando um registro de deslocamento com realimentação linear (módulo 2) que adiciona alguns estágios pré definidos ao sinal de entrada. A seqüência gerada por um registro de deslocamento de $\mathrm{m}$ estágios e periódica com período $2^{\mathrm{m}}-1$, que e a maior seqüência possível de ser produzida. A função de autocorrelação $\mathfrak{K}(\mathrm{k})$ é dual: 1 para $\mathrm{k}=0 \mathrm{e}-1 /\left(2^{\mathrm{m}}-1\right)$ para todos os demais valores. Em nosso desenvolvimento a duração da seqüência e ajustável entre $2^{2}-1$ e $2^{16}-1$. Duas saídas são disponíveis, uma retardada comum respeito à outra por um número programável de bits entre 0 e 15 . No desenvolvimento deste módulo dois dispositivos lógicos programáveis(PLS173)[6] e um gate array genérico (GAL16V8)[7] foram utilizados para reduzir a complexidade do circuito eletrônico.

\subsection{Gerador de Ruído}

Para analisar o desempenho do receptor digital é necessário ter uma fonte contínua de ruído em banda larga. As propriedades estatísticas deste sinal são também importantes, sendo o ruído branco gaussiano o mais utilizado para este propósito, por razões não óbvias mas bem documentadas pela teoria da informação [8]. Em nosso sistema a fonte de ruído é uma junção base - emissor em polarização reversa, trabalhando na região de ruptura Zener[9], seguida por um amplificador de banda larga. A largura de banda do ruído final $(3 \mathrm{~dB})$ é de $5 \mathrm{MHz}$, com nível ajustável entre $-40 \mathrm{dBm}$ e $-20 \mathrm{dBm}$. 


\subsection{Medidor de Taxa de Erro}

O desempenho de um sistema de comunicações digital pode ser analisado a partir da medida entre suas extremidades da taxa de erro de bit (BER) no receptor. Através desta medida é possível deduzir a relação sinal/ruído (S/N) na extremidade receptora, mas um grande alcance dinâmico é requerido uma vez que a probabilidade de erro diminui rapidamente com o aumento da relação $\mathrm{S} / \mathrm{N}$. O módulo proposto tem duas entradas de sinal que são comparadas sincronizadamente com o bordo de ataque ou de fuga dos pulsos de um relógio externo. As diferenças são contadas durante uma janela programável, entre 1000 e $10^{8}$ ciclos do relógio, e mostradas em um display por uma mantissa de três dígitos e um expoente de um digito. Este módulo também foi implementado com um gate array genérico programável (GAL20V8) para reduzir sua complexidade final.

\section{Caracterização de Dispositivos em Sistemas Óticos}

Com a finalidade de fornecer conhecimento sobre as principais características envolvidas na transmissão por fibra ótica, quer a nível de dispositivo quer a nível de sistema, desenvolvemos um pequeno conjunto de experiências que podem ser realizadas com o equipamento descrito anteriormente e com o auxílio de alguns equipamentos suplementares, em geral facilmente encontráveis nas instituiçóes de ensino superior. Essas experiências visam acostumar o aluno com a caracterização dos dispositivos envolvidos (Laser, LED, Fibras e Fotodetetores), com o estabelecimento de um enlace ótico (perdas de injeção de luz, conexões) e com o desempenho do sistema (comparação de sensibilidade para diferentes receptores através da medida da taxa de erro de bit - BER).

\subsection{Caracterização das Fontes de Luz}

O estudo das características de LED's e LD's como fontes de luz pode ser realizado através da fonte de corrente suplementar, permitindo obter a curva Potencia Ótica $\mathrm{x}$ Corrente no Dispositivo. Os requisitos, atendidos no equipamento desenvolvido, são uma boa estabilidade em corrente (melhor que 1\%) na faixa entre 0 e $150 \mathrm{~mA}$, e ausência de transientes na operação liga-desliga. Estes transientes podem provocar a queima dos LDs se não forem cuidadosamente eliminados. O estudo daquela curva característica pode ser feito ponto a ponto, embora seja recomendado, no caso dos LDs, que o grafismo seja realizado simultaneamentete, afim de evitar danos ao LD por excesso de potência ótica gerada. Para a medida da potência ótica é necessário o uso de um fotodetetor (ou fotocélula) de responsividade conhecida no comprimento de onda utilizado. Eventualmentete uma calibração prévia em um fototransistor infravermelho de área grande, facilmente encontrável nas lojas de componentes eletrônicos, pode servir. Um aspecto importante neste detector é uma área ativa suficientemente ampla para captar toda a radiação emitida pela fonte a distância utilizada (por precau- 
ção é conveniente que o fotodetetor esteja junto a janela de saída de luz), afim de evitar erros na medida e o dano ao componente (no caso do LD). Na figura 2 mostramos uma medida realizada com o equipamento acima mencionado.

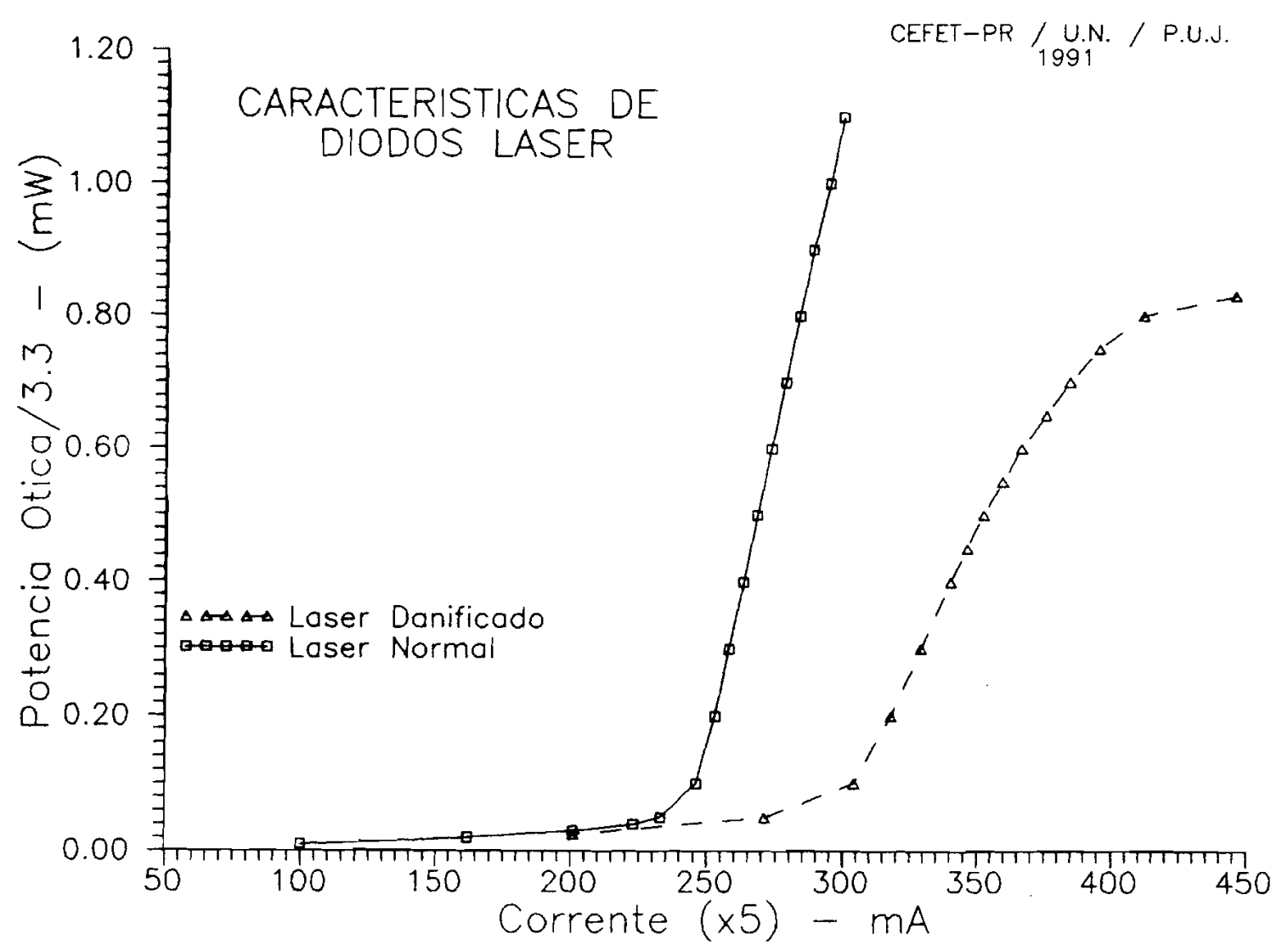

Figura 2: Curvas características de diodos laser SHARP LM023MC usados em leitores de compact disk. $\lambda_{0}=0.78 \mu \mathrm{m}$. A curva contínua (a) foi obtida para um laser normal; a curva tracejada (b) resulta de um laser anteriormente danificado por transientes.

Existindo no laboratório um sistema capaz de manter a fonte de luz a uma temperatura controlada, é possível medir aquela característica em função da temperatura, observando o envelhecimento térmico do componente. $\mathrm{Na}$ hipótese de tal sistema não estar disponível no laboratório, efeitos de aquecimento na característica de um LD podem ser observados mantendo o laser por alguns instantes numa potência ótica elevada $(\approx 2.5 \mathrm{~mW})$. Pode-se verificar o decaimento da potência emitida em função do tempo, mesmo sendo constante a corrente de polarização. Componentes danificados não devem ser descartados, pois eventualmente servem para o estudo de características anômalas, como evidenciado na figura 2, curva b - obtida com um componente anteriormente submetido a transientes de dano. 
Dependendo das facilidades experimentais disponíveis, pode também ser realizado um estudo espectral das fontes utilizadas. Neste caso a luz emitida pelo LD deve ser coletada por uma ótica adequada e selecionada por um monocromador antes de ser detetada. Isto exige um monocromador na região do infravermelho próximo (700 - 850 nm), disponível no Brasil[10]. Para os LEDs essa determinação requer uma melhor qualidade do sistema ótico envolvido é o uso de um amplificador lock-in na recuperação do sinal. O uso de um lock-in permite também estudar a diferença de espectro do LD antes e depois da corrente de limiar, ampliando a base experimental. No caso dos LDs e possível estudar a mudança nos espectros de emissão em função da corrente de polarização ou, existindo o controlador de temperatura, em função da temperatura do dispositivo.

\subsection{Características do Meio Físico}

O sistema proposto fornece uma fonte de luz comum potência ótica mensurável, sendo possível determinações de atenuação do sinal ao longo dos diversos componentes que constituem o meio físico de propagação daquele sinal. Tal meio físico inclui, na versão utilizada, um conjunto de lentes para focalização da luz sobre a face de entrada da fibra, conectores do tipo SMA para fibras de telecomunicações ou do tipo Amphenol para fibras PCS e um acoplamento variável entre duas seções de fibra ótica por meio de posicionadores, com dois graus de liberdade. É possível então realizar medidas da potência ótica disponível nos diversos segmentos do enlace, obtendo a atenuação (ou perda de inserção) de cada elemento. A tabela 1 apresenta resultados obtidos utilizando um LD como fonte de luz e fibras (aproximadamente $2 \mathrm{~km}$ ) de telecomunicaçóes.

\section{Tabela 1}

Diagrama da potência ótica medida ao longo do enlace

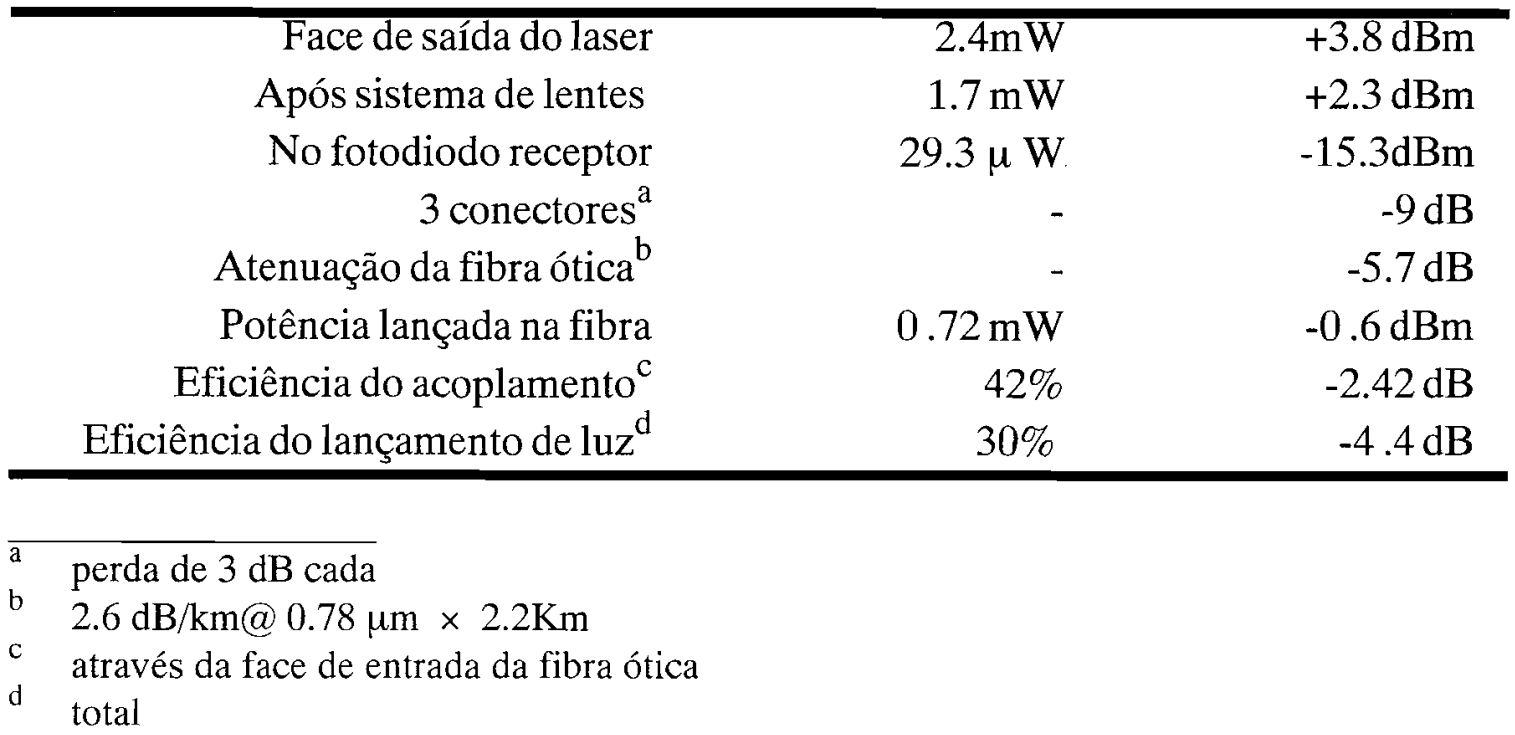


Na situação descrita naquela tabela as perdas introduzidas pela fibra e pelos diversos conectores eram conhecidas de antemão, sendo então utilizadas em conjunto com as medidas da potência ótica ao longo do enlace de fibra para a determinação da perda de acoplamento no lançamento de luz (sistema ótico-> fibra).

Montando dois segmentos de fibra sobre microposicionadores disponíveis no mercado nacional[11] pode-se realizar medidas da eficiência de acoplamento em função da separação entre as faces das fibras ou do descolamento paralelo dos respectivos eixos. Obviamente a introdução de outros componentes (goniômetros, por exemplo) permite a realização de medidas de perdas por desalinhamento angular. O uso de modulação sobre a fonte de luz e a recuperação do sinal por meio de um amplificador lock-in permitem determinar o diâmetro modal efetivo da fibra (já que as fibras utilizadas nessa janela, e por motivo de simplicidade operacional, são multimodais) usando a técnica de deslocamento transversal, padronizada para fibras monomodais pelo CСТТГ[12].

\subsection{Medidas no Sistema de Transmissão}

Nesta situação o enlace e estabelecido entre um transmissor e um receptor e os módulos do BER são conectados para fornecer uma seqüência pseudo-aleatoria de pulsos que serve como sinal de entrada para o transmissor, sendo o sinal derivado do receptor ótico enviado ao contador de BER para processamento.

Afim de permitir o estudo da sensibilidade do receptor em função da potência ótica, esta é variada por meio de ajuste externo. Pode-se utilizar um conjunto de filtros e/ou um diafragma ajustável após a fonte de luz ou então pode-se utilizar a conexão de fibras sobre os microposicionadores para introduzir uma atenuação sobre o sinal sendo propagado. A potência média atingindo o fotodetetor pode ser determinada através da corrente nele produzida e de sua responsividade espectral. Assim é possível obter-se um conjunto de pontos (Pótica $\times$ BER) que determina a curva de resposta do receptor escolhido. Usando os receptores de baixa impedância e de transimpedância é possível a comparação dos dois sistemas em termos de sensibilidade, como mostra a figura 3.

O uso de um osciloscópio para monitorar o sinal na saída do receptor permite a observação de diagramas de olho e sua degradação à medida que a potência ótica diminui. Efeitos oriundos da dispersão na fibra ótica, causando interferência intersímbolos, poderiam ser observados desde que fossem utilizadas fibras de baixo desempenho (do tipo toda plástica, por exemplo) já que a taxa máxima utilizada no sistema projetado é muito inferior à capacidade de transmissão de uma fibra normal. Aumentar simplesmente o comprimento do enlace de fibra não resolve este problema pois a atenuação do sinal seria o fator limitante do sinal sendo detectado. A solução didática para este problema está sendo estudada e será comentada futuramente. 


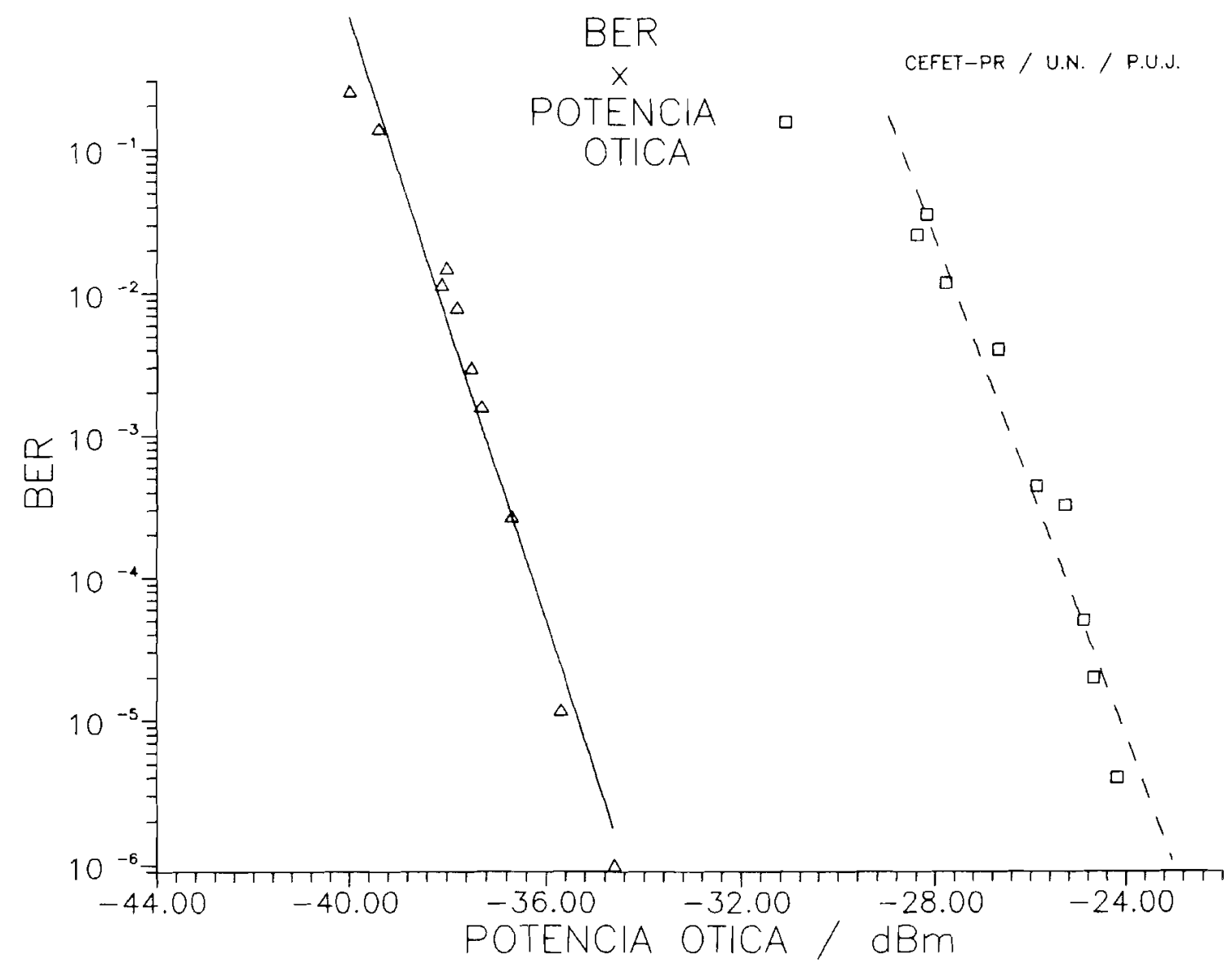

Figura 3: Sensibilidade de dois receptores usados no sistema de transmissāo: (a) reta continua - receptor de transimpedância, (b) reta tracejada-receptor de baixa impedância.

\section{Conclusões}

O desenvolvimento e uso de um equipamento dedicado de baixo custo permite realizar um conjunto importante de medidas de caracterização de um sistema de transmissão digital por fibra ótica e de seus componentes fundamentais. O treinamento adicional resultante do uso desse tipo de equipamento em laboratórios de ensino de graduaçāo seguramente permitirá uma melhor formação do profissional que irá atuar em telecomunicações, reduzindo no futuro o custo do treinamento especifico nas empresas.

\section{Referências}

[1] Edmund Scientific Company, Barrington - Pa (USA)

[2] Industrial Fiber Optics, Scottsdale - Az (USA) 
[3] P. Brack and A. Schappi, Fiberoptic Digital Transmission System, Swiss Federa Institute of Technology (ETH), Zurich,1989.

[4] Motorola Inc., Optoelectronics Device Data, 1986.

[5] J. G. Proakis, Digital Communications, McGraw Hill, 1989.

[6] Signetics, Programmable Logic Data Manual, 1986.

[7] Lattice Semiconductor Corporation, Generic Array Logic, 1988.

[8] S. Haykin, Digital Communications, John Wiley \& Sons, 1988.

[9] P. R. Gray and R. G. Meyer, Analysis and Design of Analog Integrated Circuit, John Wiley \& Sons, 1981.

[10] FUNBEC, monocromador modelo UNICROM 100; São Paulo(SP).

[11] OPTRON Micromecânica Óptica Ltda; Campinas (SP).

[12] CCITT, Rec. G.650, 1990.

Hypolito José Kalinowski nasceu em 1952 em Curitiba, PR. Possui Licenciatura em Física pela UFPr, M.Sc. e D.Sc. também em Física pela Pontifícia Universidade Católica do Rio de Janeiro. Durante 1985-1987 foi bolsista de pós-doutorado no Centro Studi e Laboratori Telecomunicazioni SpA(CSELT), Torino (Itália). Atuou como professor no Departamento de Física da PUC/RJ e no Departamento de Engenharia de Telecomunicações da UFF. Atualmente é professor adjunto no CEFET-PR, com áreas de pesquisa ligadas a aplicações de fibras óticas. O Prof. Kalinowski e membro da SBMO e SBF no Brasil, é também sócio do IEEE e da SPIE.

Angela Maria Guzmán nasceu em Bogotá, Colômbia em 1954. Ela obteve os títulos de B.Sc. e M.Sc. em Física na Universidad Nacional de Colombia(Bogotá) e o grau de Dr. rer. nat. na Ludwig Maximilian Universität (München, Germany), em 1985. Atualmente é professora associada no Departamento de Física da Universidad Nacional e conduz pesquisa em diversos aspectos de ótica guiada e não linear. A Dra. Guzmán é sócia do IEEE e da OSA (Optical Society of America) e é pesquisadora associada do International Center for Theoretical Physics, Trieste (Itália). 
Pedro Vizcaya Guarin é natural de Bogotá, tendo se graduado em Engenharia Eletrónica na Pontifícia Universidad Javeriana (Bogotá). Obteve o Mestrado em Engenharia Eletrónica no Rensselaer Politechnic Institute (USA) e ocupa o cargo de professor assistente na PUJ. Suas áreas de pesquisa ligam-se a transmissão de voz e dados, além de instrumentação eletrônica. O Prof. Vizcaya Guarin é membro do Colégio de Engenheiros de Colômbia e do IEEE e atualmente encontra-se licenciado para obter o doutorado junto ao Rensselaer Politechnical Institute.

Juán Carlos Luna e Juán Carlos Alvarez são engenheiros eletrônicos formados pela Pontifícia Universidad Javeriana (Bogotá). Sua contribuição para a parte de hardware neste trabalho foi parte de seu projeto final de curso, cujo orientador foi o Prof. Vizcaya Guarin. 